\title{
THE PRESENCE OF THREE PORTUGUESE TV NEWS CHANNELS (RTP3, SIC NOTÍCIAS, AND TVI24) ON FACEBOOK
}

\author{
Rui Rodrigues ${ }^{1}$, Sónia Ferreira*2 \\ ${ }^{1}$ Prof. Dr., Instituto Superior Miguel Torga, PORTUGAL, ruipcrodrigues@gmail.com \\ ${ }^{2}$ Prof. Dr., Escola Superior de Educação, CI \& DETS, Instituto Politécnico de Viseu, PORTUGAL, \\ sonia.ferreira@esev.ipv.pt \\ ${ }^{*}$ Corresponding Author
}

\begin{abstract}
The growing popularity of social networks, and their impact on the daily lives of consumers, contributed to news organizations marking their presence on different online platforms. In the case of Facebook, a social network that began as a personal space, it has gradually transformed into a content-sharing space (OeldorfHirsch \& Sundar, 2015). Nowadays, Facebook is the second most viewed website in Portugal (Alexa, 2016), and therefore, it has become crucial for Portuguese news agencies to be present on this social network.

Although television continues to be the main information source in Portugal, social networks, and specifically Facebook, are increasingly important in news consumption by users (ERC, 2015). This new way of news dissemination, as well as the proliferation that these contents reach in social networks, led to news agencies exploiting these new channels, both to attract new audiences, and to redirect users to their own websites (Castillo, El-Haddad, Pfeffer, \& Stempeck, 2014). Thus, it is important to understand how, and what kind of content these agencies put on their Facebook channels, as well as the strategies they use to share these same contents.

This study aims to understand how the main news channels of Portuguese TV (RTP3, SIC Notícias, and TVI24) manage and use the social network Facebook to share news contents. To this end, the authors collected quantitative data of all posts placed on Facebook between February 8 and February 142016. Approximately 1063 posts were collected and analysed from the three Facebook pages. The results indicate that two of the three channels extensively used their Facebook pages to share and target content to their official websites. Regarding the news sources and type of media used, the three Portuguese TV news channels use similar strategies. However, in what concerns the main thematic and quantity of messages per day, as well as the level of redundancy of information, the three channels operate their pages differently.
\end{abstract}

Keywords: TV News Channels, Facebook, News Consumption

\section{INTRODUCTION}

Nowadays, people have a variety of services that allow them to consume information more than ever. This technological evolution, particularly with regard to the ability that an individual has to consume and distribute content, allowed to establish new dynamics, both collaboration and cooperation (Cádima, 2013). With the 
advent of the Internet, Web 2.0 and social network sites (SNS), the individual has a more active role in access and content sharing. The user is no longer a receiver of information, it is also part of this process (Gluck \& Sales, 2008). It is important that news organizations realize that the individual expectations are changing. An example of this is the tendency to consume more television on the Internet. According to data collected by Public and Media Consumption report, conduced by the regulator for the media in Portugal $(E R C)^{1}$, the effect of the Internet increasingly influenced the traditional media (ERC, 2015). In a reality where the diversity of services to the public is huge, it is important that television, specifically the news channels, adapt and have their presence in other formats, taking advantage of new media to differentiate and continue to attract their audiences. Actually, some of these media are important players in the reception and dissemination of information, as is the case of Facebook and Twitter services. The news organizations see these services as market opportunities, as well as content distributors (Hermida, Fletcher, Korell, \& Logan, 2012).

In the Portuguese context, Facebook plays a crucial role, since it is the second most viewed site in Portugal (Alexa, 2016). The social network Facebook allows new ways of sharing content, and enable users to comment and interact with the content published by news organizations (Oeldorf-Hirsch \& Sundar, 2015). In recent years, the use of Facebook pages by the TV news channels has become a common practice (Castillo et al., 2014). Television is no longer isolated in the transmission of content, sharing this function with other services such as Facebook, Twitter and the official TV news channels websites. This study aims to understand how the main news channels of Portuguese TV manage and use the social network Facebook to share news contents.

The news consumption is changing quickly and audiences are more divided. Nowadays, the consumers do not seek a single source of news, using your entire network for content consumption (Aitamurto \& Lewis, 2013). Thus, it is important to understand the relationship between TV news channels and social networks, and the role they play by providing new ways to consume and distributing contents.

\section{LITERATURE REVIEW}

Once the audiences are more divided, as well as the technological advances that have occurred in recent years, now the main TV news channels are not limited only to traditional media, and have other concerns and areas of activity, such as SNS's. These TV news channels have an increasingly cross presence, since users consume news in many contexts. According to the Reuters Institute report, the consumption of news in other services and platforms, such as smartphones and tablets, has been growing (Newman, Levy, \& Nielsen, 2015). The main television stations are developing new products and services for different platforms, so your users can view and follow their content anytime, anywhere. Therefore, these content producers take the content that are developed primarily for television and adapt these contents to other supports and media. Today, it is possible to see the same content in different platforms, or these contents are adapted and applied to other contexts, for example SNS (Canelas, 2011). In the case of television news, the same strategies are applied, and the user can view and follow the news in different supports. Some of these options are provided by the main news channels of Portuguese TV, such as RTP3 ${ }^{2}$, SIC Notícias ${ }^{3}$, and TVI24. ${ }^{4}$. Thanks to these options, people now have a diversity of solutions to follow the news on other services, such as official websites and SNS. Once users have access to the Internet, they can access news content whenever they want.

The audience, particularly its fragmentation, play an important role in the choices that TV news channels have been doing. The three most important news channels of Portuguese TV (RTP3, SIC Notícias and TVI24) realized this phenomenon and have their presence on other platforms. Television is no longer isolated in the dissemination of news, sharing this function with other digital platforms (Cádima, 2010). Although television remains the primary source of news consumption (ERC, 2015; Newman et al., 2015), nowadays, it is possible to follow these programs and their contents, according to the needs and preferences of the user. In this context, social media has increasingly been used to news consumption. According to the Reuters Institute Digital News 2015 and ERC reports, these services are already one of the major sources in the consumption and sharing of news. In Portugal, the SNS are the second resource for checking news, and $69 \%$ of the users use the SNS's to have knowledge about new online contents (ERC, 2015, p. 42). Since

\footnotetext{
${ }^{1}$ It is an autonomous institution that has the function of supervising and regulate the media in Portugal.

2 http://www.rtp.pt/play/direto/rtp3

3 http://sicnoticias.sapo.pt/

4 http://www.tvi24.iol.pt/
} 
SNS's, particularly Facebook, attracts more visitors than the official websites of TV news channels, these companies have realized that using these SNS, they can redirect users to their own websites, and thereby increasing the services that provide contents (Castillo et al., 2014; Hille \& Bakker, 2014). Many news organizations, specially the TV news channels, already see the SNS's as an important part in the relationship with your audience. An example of this are the resources that these news organizations already spend on SNS to keep your audience constantly updated (Ju, Jeong, \& Chyi, 2014). The SNS's represent an evolution of the consumption made in traditional media "where the dynamics of publication and distribution of news are being reshaped by networked publics" (Hermida et al., 2012, p. 816).

Nowadays, what matters is not the importance of information, but distribute news that the audience like. In Portugal, some authors have studied and categorized the thematic of the TV news channels (Brandão, 2009; Lopes, 1999; Silveira, Cardoso, \& Neto, 2010). According to Lopes (1999), the thematic of the news can be divided into two types: national news and international news. This division allows the geographically delimitation of the news that take place in the country (national news), and the news that correspond to international events (international news). These works, and the data collected by reports abovementioned (ERC, 2015; Newman et al., 2015), it will be important to classify the themes presented in the publications placed on Facebook pages of the news channels of Portuguese TV analysed for this paper.

\subsection{Facebook and Social Media}

Through the convergence and integration of different news media, the information is not available in one single support, and is broadcasted in different media and platforms (Canelas, 2011). The TV news channels have been adapting, using digital media to differentiate themselves from their competitors, and at the same time continue to capture their audience. Given this fact and the fragmentation of audiences, both the traditional media as the digital media, it is necessary that the content serves the purpose and needs of the audience (Sobral, 2012). The transmedia context, and the ability of the user to view and access information anytime, anywhere (Jenkins, 2006), has been exploited by news organizations. These new contexts have enabled the consumption of contents in different formats and supports, as can be seen from the Public and Media Consumption report from ERC (2015).

Another case that should be included is the increasing use of SNS's by the TV news channels. In the case of Facebook, a SNS that has over 1.1 billion users worldwide, this is no longer just a personal space and a social network where users share content, and is starting to become a global utility space, both for users and news organizations (Jacobson, 2013). In Portugal, the social network Facebook gains an added importance when compared to other countries, because the Facebook is used by $76 \%$ of users to access the news, while in other countries this percentage is only $35 \%$ (ERC, 2015, p. 42). The presence of TV news channels on Facebook has the main purpose of publishing the news. As those news are shared on Facebook, they tend to generate comments from users, influencing the consumption of content by those who read the comments (Hille \& Bakker, 2014). Facebook becomes an excellent example of user participation in the news content, abandoning a position of passive users of news contents, and assuming a role of content sharing. For the users, this sharing and discussion of content create a self-sense of information control, and is also an important source of news for your network (Oeldorf-Hirsch \& Sundar, 2015). For news organizations, the content sharing made by users, allows these content to reach a larger number of people. Because that content often has a link that redirects the user for the full article (Ju et al., 2014; Oeldorf-Hirsch \& Sundar, 2015), ultimately, sharing this content, allows news organisations to increase the number of visits of their official websites.

In the case of TV news channels, the social network Facebook is used as a complement of their official websites. Sometimes, these channels also use their Facebook pages to share videos that can be viewed directly on Facebook, or even publish contents that satisfy users with only the information placed in this publication (Castillo et al., 2014). However, the common practice is to share only a link with a brief information, in order to redirect the audience to their official websites. Most of all, it is important that the news organizations, specifically the TV news channels, adapt news content for different supports, in order to improve the user experience. It is necessary that these news organizations create communication strategies, whether for SNS's, whether for viewing content in other platforms.

\section{RESEARCH HYPOTHESIS}

Conducted the literature review and selected the news channels of Portuguese TV (RTP3, SIC Notícias, and TVI24), the research developed and reported in this paper is based on three research hypotheses: 
H1: Being SIC Notícias and TVI24 the TV news channels most consulted online, the number of posts on Facebook is also greater in these two channels, and fluctuate depending of the time of the day.

Based on the number of "Likes" on the Facebook pages of RTP3, SIC Notícias, and TVI24, as well as their importance on the consumption of online news (ERC, 2015), this research hypothesis aims to understand if there are a relation between the number of "Likes" of each Facebook page and the number of publications. For the selection of these three TV news channels the authors take into account the Public and Media Consumption from ERC (2015). According to this report, the three TV news channels more consulted online ${ }^{5}$ are: SIC Notícias $(21 \%)$, TVI24 $(15 \%)$ and RTP3 ${ }^{6}(5 \%)$. It is also intended verify whether the three TV News channels, the number of publications varies throughout the day. For that purpose, the ERC report was consulted again. According to this report (ERC, 2015), users consume more news early in the morning (55\%) and the beginning and end of the night ( $42 \%$ and $41 \%$ respectively). In short, this hypothesis aims to understand how the TV news channels manage their Facebook pages, taking into account their audience.

H2: In terms of news sources, RTP3, SIC Notícias, and TVI24, intend to use the Facebook to redirect your audience to their official websites, and these news' are usually text with complementary information.

For this second hypothesis the authors intend to analyse whether the three main news channels of Portuguese TV, use their Facebook pages as a tool to redirect your audience to their official websites (Ju et al., 2014; Oeldorf-Hirsch \& Sundar, 2015), or also used for share content from other sources. It is also intend to understand if the news posted on Facebook pages use text only or other format (images or video), and if there are redundancy between the information placed in the publication and the link that redirect the users to their official websites. According the Public and Media Consumption from ERC (2015), users mainly read news in text format (42\%) and occasionally watch videos (37\%).

H3: In terms of thematic, the news content most published on the Facebook pages of RTP3, SIC Notícias and TVI24 are "National News" and news about "Health", "Education" and "Sports".

Finally, the last hypothesis aims to understand if there is an association between the thematic published by the TV news channels and user preferences. To formalize this hypothesis, the authors considered the results of thematic interests of users reported in the Public and Media Consumption from ERC (2015). Furthermore, some authors refer that the audience and the profile of users can influence the content published on Facebook (Jacobson, 2013). It is also important to mention that the categorization of thematic is carried out taking into account the dominance of thematic. In other words, if a publication has various thematic, it is the main thematic that will be categorized.

\section{METHOD}

This paper study the presence of the three main TV news channels of Portuguese TV: RTP3, SIC Notícias and TVI24 on their Facebook pages. These data were collected in Facebook pages of RTP3, SIC Notícias, and TVI24, between the $8^{\text {th }}$ and $14^{\text {th }}$ of February (one week). Statistical analysis was performed using IBM SPSS 23.0 - Statistical Package for Social Sciences, and the parameters analysis was:

i. Posts: The number of publications made in the different Facebook pages;

ii. Time of the day: It concerns the times of day in which publication was made by the three TV news channels. The authors chose to follow the time of the day mentioned on ERC report (ERC, 2015): "in the morning" (7am-10am), "late morning" (10am-1pm), "early afternoon" (1pm-4pm), "afternoon" $(4 \mathrm{pm}-7 \mathrm{pm})$, "in the early night"(7pm-10pm), and "the end of the night" (10pm-1am);

iii. Original Post: If there are publications made exclusively for Facebook, or publications redirect the users for official websites of the TV news channels;

iv. Source of news content: If the news content published by the TV news channels on their Facebook pages redirect the users to their official websites or other sources;

v. The format of news content: Text, Images or Video;

vi. Information Type: If the text that accompanied the link of the news content is redundant, complementary, or do not have any text;

\footnotetext{
${ }^{5}$ Only the news channels of Portuguese TV were taken into account, and not the portuguese generalist channels, such as SIC, TVI and RTP1.

${ }^{6}$ In 2016, RTP Informação changed its name to RTP3.
} 
vii. Thematic: It concerns to the main thematic present in each Facebook publication. The same news may have sometimes more than one thematic identified. In these cases, it is the main thematic that will be categorized. The thematic are based on the "Reuters Institute Digital News Report", 2015, but the authors added the categories "Opinion" and "Other". The authors also opted to separate the category "Society" of "Entertainment/Celebrities", and rename the category for "Country/Society". This category represents all the local/region/town news. Thus, the categories under consideration are: "Country/Society", "Economy", "Health", "Education", "Financial/Business", "Entertainment/Celebrities", "Art and Culture", "Politics", "Science and Technology", "Sport", "Humorous/Satirical/Unusual", "Opinion", and "Other".

\section{RESULTS \& DISCUSSION}

\subsection{Number of publications and "Likes" on Facebook pages}

During the period of February 8 to February 142016 the three news channels of Portuguese TV have published 1063 posts. As can be seen in Table 1, RTP3 have made 188 publications, SIC Notícias 424 publications, and TVI24 188 publications. Furthermore, the TV news channel that has the highest number of "Likes" on their Facebook page is the SIC Notícias (876.856), followed by TVI24 and RTP3 (486.843 and 254.554 respectively). The data collected of these "likes" was made on February 5, 2016

Table 1 - RTP 3, SIC Notícias and TVI24 | Page Likes and number of publications

\begin{tabular}{|l|c|c|}
\hline TV News Channel & Page Likes & Publications \\
\hline RTP3 & 254.554 & 188 \\
\hline SIC Notícias & 876.856 & 424 \\
\hline TVI24 & 486.843 & 451 \\
\hline Total & 1618.253 & 1.063 \\
\hline
\end{tabular}

Note: This Facebook pages did not provide their dates of creation. This may be interfering with the number of "Likes" on each page.

Overall, despite the SIC Notícias is the channel that has the highest number of "Likes" on their Facebook page (876.856), is the TVI24 channel that publishing more news content during the seven days of analysis $(\mathrm{N}=451)$.

Considering the time of the day that the three TV news channels publish on their Facebook pages, the data presented in Table 2 indicate that RTP3 publish more news in period from "7pm-10pm" (23.9\%), and SIC Notícias in the period from "10am-1pm" (24.8\%). The TVI24 channel there is no time of the day that stands out.

Table 2 - Number of posts by time of the day in RTP3, SIC Notícias and TVI24 news channels

\begin{tabular}{|l|c|c|c|c|c|c|c|c|}
\hline \multirow{3}{*}{ Time of the day } & \multicolumn{9}{|c|}{ Channels } \\
\cline { 2 - 10 } & \multicolumn{2}{|c|}{ RTP3 } & \multicolumn{7}{c|}{ SIC Notícias } & \multicolumn{2}{c|}{ TVI24 } & \multicolumn{2}{c|}{ TOTAL } \\
\cline { 2 - 10 } & $f$ & $\%$ & $f$ & $\%$ & $f$ & & $f$ & $\%$ \\
\hline 7am-10am & 21 & 11.2 & 81 & 19.1 & 50 & 11.4 & 152 & 14.3 \\
\hline 10am-1pm & 37 & 19.7 & 105 & 24.8 & 74 & 16.4 & 216 & 20.3 \\
\hline 1pm-4pm & 34 & 18.1 & 76 & 17.9 & 72 & 16.0 & 182 & 17.1 \\
\hline 4pm-7pm & 37 & 19.7 & 55 & 13.0 & 67 & 14.9 & 159 & 15.0 \\
\hline 7pm-10pm & 45 & 23.9 & 52 & 12.3 & 77 & 17.1 & 174 & 16.4 \\
\hline 10pm-1am & 14 & 7.4 & 53 & 12.5 & 75 & 16.6 & 142 & 13.4 \\
\hline 1am-7am & 0 & 0.0 & 2 & 0.5 & 36 & 8.0 & 38 & 3.6 \\
\hline Total & 188 & 100 & 424 & 100 & 451 & 100 & 1.063 & 100 \\
\hline
\end{tabular}

Some of the results are consistent with the hypothesis proposed in this research $(\mathrm{H} 1)$. These results suggest 
a relation between the number of "likes" on Facebook pages of the three TV news channels, and the number of publications produced by each channel. However, throughout the day, the results indicate that these TV news channels do not take into account the fact that users consume more news early in the morning and the beginning and end of the night (ERC, 2015). The only exception is RTP3 in the period between "7pm-10pm" (beginning of the night).

\subsection{Source of the news content on Facebook pages}

According to the data presented in Tables 3 and 4, the three TV news channels of Portuguese TV do not have original publications on Facebook page, and redirect your audience to their official websites. Of all the publications made by the three TV news channels, only $2.4 \%$ are made intentionally for their Facebook pages, and only $4.8 \%$ did not redirect the users to their official websites.

Table 3 - Original publications on Facebook pages of RTP3, SIC Notícias and TVI24

\begin{tabular}{|l|c|c|c|c|c|c|c|c|}
\hline \multirow{2}{*}{$\begin{array}{l}\text { Redirect to official } \\
\text { website }\end{array}$} & \multicolumn{9}{|c|}{ RTP3 } & \multicolumn{2}{c|}{ SIC Notícias } & \multicolumn{2}{c|}{ TVI24 } & \multicolumn{2}{c|}{ TOTAL } \\
\cline { 2 - 9 } & $f$ & $\%$ & $f$ & $\%$ & $f$ & $\%$ & $f$ & $\%$ \\
\cline { 2 - 10 } & & & & & & & & \\
\hline No & 1 & 0.5 & 23 & 5.4 & 1 & 0.2 & 25 & 2.4 \\
\hline Yes & 187 & 99.5 & 401 & 94.6 & 450 & 99.8 & 1.038 & 97.6 \\
\hline Total & 188 & 100 & 424 & 100 & 451 & 100 & 1.063 & 100 \\
\hline
\end{tabular}

Table 4 - Source of news content on Facebook pages of RTP 3, SIC Notícias and TVI24

\begin{tabular}{|l|c|c|c|c|c|c|c|c|}
\hline \multirow{2}{*}{$\begin{array}{l}\text { Source of news } \\
\text { content }\end{array}$} & \multicolumn{2}{|c|}{ RTP3 } & \multicolumn{1}{c|}{ SIC Notícias } & \multicolumn{2}{c|}{ TVI24 } & \multicolumn{2}{c|}{ TOTAL } \\
\cline { 2 - 9 } & $f$ & $\%$ & $f$ & $\%$ & $f$ & $\%$ & $f$ & $\%$ \\
\cline { 2 - 10 } & & & & & & & & \\
\hline Internal & 187 & 99.5 & 381 & 89.9 & 444 & 98.4 & 1.012 & 95.2 \\
\hline External & 1 & 0.5 & 43 & 10.1 & 7 & 1.6 & 51 & 4.8 \\
\hline Total & 188 & 100 & 424 & 100 & 451 & 100 & 1.063 & 100 \\
\hline
\end{tabular}

Specifically, in 188 publications made by RTP3, 187 of them redirect users to their official website (99.5\%). The same applies to SIC Notícias and TVI24, 94.6\% and 99.8\% respectively. Moreover, in terms of "Source of news content", the RTP3 just published one news content that redirect the user to an external source (0.5\%), while SIC Notícias published 43 external sources (10.1\%), and TVI24 only $1.6 \%$ were external sources. As refer Ju et al. (2014) and Oeldorf-Hirsch and Sundar (2015), the news organizations use Facebook to redirect the audience to their official webpages. These results reinforce these studies.

About the format of news content published in Facebook page of the three TV news channels, the data presented in Table 5 indicate that most of them are text with an image preview (98.6\%). Only a few contents are in video format $(1.4 \%)$.

Table 5 - Format of news content published on Facebook pages of RTP 3, SIC Notícias and TVI24

\begin{tabular}{|l|c|c|c|c|c|c|c|c|}
\hline \multirow{2}{*}{ Format of news content } & \multicolumn{9}{|c|}{ Channels } \\
\cline { 2 - 10 } & \multicolumn{2}{|c|}{ RTP3 } & \multicolumn{2}{c|}{ SIC Notícias } & \multicolumn{2}{c|}{ TVI24 } & \multicolumn{2}{c|}{ TOTAL } \\
\cline { 2 - 10 } & $f$ & $\%$ & $f$ & $\%$ & $f$ & $\%$ & $f$ & $\%$ \\
\hline Text \& Images Preview & 186 & 98.9 & 421 & 99.3 & 441 & 97.8 & 1.048 & 98.6 \\
\hline Video & 2 & 1.1 & 3 & 0.7 & 10 & 2.2 & 15 & 1.4 \\
\hline Total & 188 & 100 & 424 & 100 & 451 & 100 & 1.063 & 100 \\
\hline
\end{tabular}

These results seem to comply with the user preferences. In fact, according the Public and Media Consumption from ERC (2015), users mainly read news in text format and occasionally watch videos. 
Finally, according to Table 6, the text that accompanied the link of the news content of the three TV news channels, is usually complementary (71.3\%). However, in the case of SIC Noticias these texts vary. Sometimes these publications have information redundancy $(25.2 \%)$, or has no accompanying text $(34.7 \%)$.

Table 6 - Redundancy between the information and the links provided in the publications of the Facebook pages of RTP 3, SIC Notícias and TVI24

\begin{tabular}{|l|c|c|c|c|c|c|c|c|}
\hline \multirow{3}{*}{ Information type } & \multicolumn{9}{|c|}{ Channels } \\
\cline { 2 - 10 } & \multicolumn{2}{|c|}{ RTP 3 } & \multicolumn{1}{|c|}{ SIC Notícias } & \multicolumn{2}{c|}{ TVI24 } & \multicolumn{2}{c|}{ Total } \\
\cline { 2 - 10 } & $f$ & $\%$ & $f$ & $\%$ & $f$ & $\%$ & $f$ & $\%$ \\
\hline Without Information & 6 & 4.8 & 147 & 34.7 & 15 & 3.3 & 171 & 16.1 \\
\hline Redundancy of Information & 23 & 12.2 & 107 & 25.2 & 4 & 0.9 & 134 & 12.6 \\
\hline Complementary of Information & 156 & 83.0 & 170 & 40.1 & 432 & 95.8 & 758 & 71.3 \\
\hline Total & 188 & 100 & 424 & 100 & 451 & 100 & 1.063 & 100 \\
\hline
\end{tabular}

This result appears to be related with the hypothesis formulated in this research $(\mathrm{H} 2)$. In terms of news sources, RTP3, SIC Notícias, and TVI24, intend to use the Facebook to redirect your audience to their official websites (97.6\%), and these news' are usually text (98.6\%), with complementary information (71.3\%).

\subsection{The thematic of the news content}

Overall, as can be seen in Table 7, in terms of percentage, the thematic most published by the three TV news channels on their Facebook pages are: "Country/Society" (40.5\%), "Politic" (11.1\%), and "Sport" $(10.4 \%)$. On the contrary, the thematic less published are: "Education" $(0.8 \%)$, "Opinion" $(2.4 \%)$ and "Financial/Business" (2.6\%). Specifically, RTP3, SIC Notícias and TVI24, share the same thematic with the highest number of publications "Country/Society" and "Politic".

Table 7 - Thematic of the news content on Facebook Pages of RTP 3, SIC Notícias and TVI24

\begin{tabular}{|l|c|c|c|c|c|c|c|c|}
\hline \multirow{2}{*}{ Thematic } & \multicolumn{9}{|c|}{ Channels } & \multicolumn{2}{c|}{ Total } \\
\cline { 2 - 9 } & \multicolumn{2}{|c|}{ RTP 3 } & \multicolumn{2}{|c|}{ SIC Notícias } & \multicolumn{2}{c|}{ TVI24 } & \multicolumn{2}{c|}{} \\
\cline { 2 - 9 } & $f$ & $\%$ & $f$ & $\%$ & $f$ & $\%$ & $f$ & 40.5 \\
\hline Country/Society & 48 & 25.5 & 158 & 37.3 & 225 & 49.9 & 431 & 4.9 \\
\hline Economy & 18 & 9.6 & 34 & 8.0 & 31 & 6.9 & 83 & 7.8 \\
\hline Health & 7 & 3.7 & 13 & 3.1 & 16 & 3.5 & 36 & 3.4 \\
\hline Education & 2 & 1.1 & 2 & 0.5 & 5 & 1.1 & 9 & 0.8 \\
\hline Financial/Business & 9 & 4.8 & 10 & 2.4 & 9 & 2.0 & 28 & 2.6 \\
\hline Entertainment/Celebrities & 1 & 0.5 & 23 & 5.4 & 34 & 7.5 & 58 & 5.5 \\
\hline Art and Culture & 13 & 6.9 & 26 & 6.1 & 17 & 3.8 & 56 & 5.3 \\
\hline Politic & 30 & 16.0 & 42 & 9.9 & 46 & 10.2 & 118 & 11.1 \\
\hline Science and Technology & 4 & 2.1 & 24 & 5.7 & 10 & 2.2 & 38 & 3.6 \\
\hline Sport & 32 & 17.0 & 54 & 12.7 & 25 & 5.5 & 111 & 10.4 \\
\hline Humorous/Satirical/Unusual & 1 & 0.5 & 11 & 2.6 & 17 & 3.8 & 29 & 2.7 \\
\hline Opinion & 14 & 7.4 & 10 & 2.4 & 1 & 0.2 & 25 & 2.4 \\
\hline Other & 9 & 4.8 & 17 & 4.0 & 15 & 3.3 & 41 & 3.9 \\
\hline Total & 188 & 100 & 424 & 100 & 451 & 100 & 1.063 & 100 \\
\hline
\end{tabular}

When analysed according to "National News" and "International News", the data observed in Table 8 are unanimous. The three TV news channels published on their Facebook pages more "National News" (62.3\%) than "International News" (37.7\%). 
Table 8 - National or International News in RTP3, SIC Notícias and TVI24

\begin{tabular}{|l|c|c|c|c|c|c|c|c|}
\hline \multirow{3}{*}{} & \multicolumn{9}{|c|}{ Channels } \\
\cline { 2 - 10 } & \multicolumn{2}{|c|}{ RTP 3 } & \multicolumn{1}{|c|}{ SIC Notícias } & \multicolumn{2}{c|}{ TVI24 } & \multicolumn{2}{c|}{ Total } \\
\cline { 2 - 10 } & $f$ & $\%$ & $f$ & $\%$ & $f$ & $\%$ & $f$ & $\%$ \\
\hline National News & 116 & 61.7 & 261 & 61.6 & 285 & 63.2 & 662 & 62.3 \\
\hline International News & 72 & 38.3 & 163 & 38.4 & 166 & 36.8 & 401 & 37.7 \\
\hline Total & 188 & 100 & 424 & 100 & 451 & 100 & 1.063 & 100 \\
\hline
\end{tabular}

According to the ERC report (2015), Portuguese consumers consider the "National News" as the most important news (92\%), and in terms of thematic, the consumers show more interest in news about "Sports", "Health" and "Education".

Considering the results obtained, part of the third hypothesis can be confirmed $(\mathrm{H} 3)$. The results indicate that the news content published on the three Facebook pages of TV news channels have no association between the thematic published by the TV news channels and user preferences, except the news content about "Sport".

\section{CONCLUSION \& FUTURE WORK}

This study demonstrates the importance that SNS's have in news consumption by users. These services, specifically the Facebook, are now important players in the reception and dissemination of the news content.

The results obtained in this paper suggest a relation between the number of "likes" on Facebook pages, and the number of publications produced by each channel. Considering the time of the day which TV news channels most publish news content, the results indicate that these TV news channels do not take into account the fact that users consume more news early in the morning and the beginning and end of the night (ERC, 2015).

As would be expected, RTP3, SIC Notícias, and TVI24, intend to use their Facebook pages to redirect your audience to their official websites (Ju et al., 2014; Oeldorf-Hirsch \& Sundar, 2015). The common practice of these TV news channels is to share only a link with a brief information. These links are usually accompanied with complementary information. These results seem to comply with the user preferences, who preferred to read news in text format and occasionally watch videos (ERC, 2015).

In terms of thematic, these paper concludes that the news content published on the three Facebook pages of RTP3, SIC Notícias, and TVI24 have no association between the thematic published by these channels and user preferences, except the news content about "Sport".

Despite the limitations identified on this paper, specifically in terms of the period of data collected (one week), in the future it is expected to increase the analysis period and to extend it to include other TV news channels.

Concluding, the collected data also reinforce the need for news organizations to raise awareness about the importance of studies like this paper and previous studies, in order to take advantage of the potential that SNS, like Facebook, can bring to journalism.

\section{ACKNOWLEDGEMENTS}

The Instituto Politécnico de Viseu, the Center for Studies in Education, Technologies and Health (CI\&DETS) and the Portuguese Foundation for Science and Technology (FCT).

\section{REFERENCE LIST}

Aitamurto, T., \& Lewis, S. C. (2013). Open innovation in digital journalism: Examining the impact of Open APIs at four news organizations. New Media \& Society, 15(2), 314-331.

Alexa. (2016). Top Sites in Portugal. Retrieved from http://www.alexa.com/topsites/countries/PT

Brandão, N. (2009). As Categorias Temáticas das Notícias dos Telejornais de Horário Nobre Portugueses. 
Paper presented at the $6^{\circ}$ Congresso SOPCOM, Lisboa.

Cádima, F. R. (2010). A Televisão Pública face aos Novos Ambientes Web. Paper presented at the II Congreso Internacional Comunicacion 3.0, Salamanca.

Cádima, F. R. (2013). New Problems for Journalism in the Digital Age. Paper presented at the Understanding Communications in the New Media Era, Istanbul.

Canelas, C. (2011). Os Efeitos da Convergência nos Media Noticiosos. Paper presented at the Congresso Nacional "Literacia, Media e Cidadania", Braga.

Castillo, C., El-Haddad, M., Pfeffer, J., \& Stempeck, M. (2014). Characterizing the life cycle of online news stories using social media reactions. Paper presented at the Proceedings of the 17th ACM conference on Computer supported cooperative work \& social computing.

ERC. (2015). Públicos e Consumos de Média: O consumo de notícias e as plataformas digitais em portugal e em mais dez países. Retrieved from Lisboa:

Gluck, M., \& Sales, M. (2008). The Future of Television? Advertising, technology and the pursuit of audiences. Retrieved from

Hermida, A., Fletcher, F., Korell, D., \& Logan, D. (2012). Share, like, recommend: Decoding the social media news consumer. Journalism Studies, 13(5-6), 815-824.

Hille, S., \& Bakker, P. (2014). Engaging the Social News User: Comments on News Sites and Facebook. Journalism Practice, 8(5), 563-572.

Jacobson, S. (2013). Does audience participation on Facebook influence the news agenda? A case study of the Rachel Maddow Show. Journal of Broadcasting \& Electronic Media, 57(3), 338-355.

Jenkins, H. (2006). Convergence Culture: Where Old and New Media Collide. New York: New York University Press.

Ju, A., Jeong, S. H., \& Chyi, H. I. (2014). Will social media save newspapers? Examining the effectiveness of Facebook and Twitter as news platforms. Journalism Practice, 8(1), 1-17.

Lopes, F. (1999). O Telejornal e o Serviço Público. Coimbra: Minerva Editora.

Newman, N., Levy, D., \& Nielsen, R. (2015). Reuters Institute Digital News Report 2015: Tracking the Future of News. Retrieved from Oxford:

Oeldorf-Hirsch, A., \& Sundar, S. S. (2015). Posting, commenting, and tagging: Effects of sharing news stories on Facebook. Computers in Human Behavior, 44, 240-249.

Silveira, J., Cardoso, G., \& Neto, P. (2010). Telejornais no início do Século XXI: Edições Colibri.

Sobral, F. A. (2012). Televisão em Contexto Português: Uma Abordagem Histórica e Prospetiva. Millenium, $42,17$. 